\title{
Transient carriage and low-level colonization of orally administrated lytic and temperate phages in the gut of mice
}

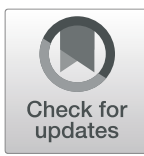

Hongduo Bao ${ }^{1,2}$, Hui Zhang ${ }^{1}$, Yan Zhou', Shujiao Zhu', Maoda Pang ${ }^{1}$, Khashayar Shahin $^{1}$, Ademola Olaniran ${ }^{3}$, Stefan Schmidt ${ }^{2^{*}}$ and Ran Wang ${ }^{1^{*}}$ (D)

\begin{abstract}
Many studies have shown the efficacy of phage therapy in reducing gastrointestinal pathogens. However, it is unclear whether phages can successfully colonize the gut when administered in an adequate amount for a long time. About $1 \times 10^{8} \mathrm{PFU} / \mathrm{mL}$ of purified lytic phage PA13076 or temperate phage BP96115 were fed daily to mice via drinking water over 31 days, to elucidate the distribution of phages in the gastrointestinal tract. At day 16 and 31 , six different segments of the gastrointestinal tract with their contents, including stomach, duodenum, jejunum, ileum, cecum, colon, and fresh feces, were aseptically collected. The phage titers were determined using the double-layered plate method with S. Enteritidis ATCC 13076 or S. Pullorum SPu-109 used as host cells. The results indicated that a small portion of administered phages survived exposure to gastric acid and entered the intestinal tract. The prevalence of phages in the gastrointestinal tract was lower than $1 \%$ of the primary phage count. Highest phage titers were detected in the cecum with $10^{4} \sim 10^{5} \mathrm{PFU} / \mathrm{g}$, and most of the phages were eliminated from the body via feces with $10^{6} \mathrm{PFU} / \mathrm{g}$. On day 16 and day 31 , the same level of phage titers in different segments of the gastrointestinal tract indicated that the colonization of phages had reached saturation at day 16 . These results demonstrate transient phage carriage and low-level colonization of orally administrated lytic and temperate gut phages in mice.
\end{abstract}

Keywords: Lytic phage, Temperate phage, Colonization, Gut, Mice

\section{Introduction}

The colonization of livestock by pathogenic bacteria poses a significant problem in industrialized farming and is a major source of human foodborne illness. The critical role of intestinal phages is their capability in controlling local bacterial populations. Oral phage administration is primarily used to treat gastrointestinal and

\footnotetext{
*Correspondence: schmidts@ukzn.ac.za; ranwang@jaas.ac.cn

${ }^{2}$ Discipline of Microbiology, School of Life Sciences, College of Agriculture, Engineering and Science, University of KwaZulu-Natal, Pietermaritzburg Campus, Private Bag X01, Pietermaritzburg 3201, South Africa

${ }^{1}$ Key Laboratory of Control Technology and Standard for Agro-product Safety and Quality, Jiangsu Key Laboratory for Food Quality and Safety-State Key Laboratory Cultivation Base of Ministry of Science and Technology, Institute of Food Safety and Nutrition, Jiangsu Academy of Agricultural Sciences, Nanjing 210014, China

Full list of author information is available at the end of the article
}

other extraintestinal infections (Galtier et al. 2016; Zelasko et al. 2017). Moreover, it is generally regarded as the most convenient delivery route for large-scale animal breeding (Kim et al. 2013; Piewngam et al. 2018). Additionally, oral phage administration is an effective means to treat gastrointestinal tract infections (e.g., in calves, lambs, and piglets) and diseases located outside of the digestive tract while leaving the native flora unperturbed (Ahmadi et al. 2016). The challenge is the phage stability when exposed to the highly acidic and proteolytic environment of the stomach. Protection from gastric acidity by methods such as polymer or liposome microencapsulation may increase the efficacy of orally administered phages (Malik et al. 2017).

(c) The Author(s). 2020 Open Access This article is licensed under a Creative Commons Attribution 4.0 International License, which permits use, sharing, adaptation, distribution and reproduction in any medium or format, as long as you give appropriate credit to the original author(s) and the source, provide a link to the Creative Commons licence, and indicate if changes were made. The images or other third party material in this article are included in the article's Creative Commons licence, unless indicated otherwise in a credit line to the material. If material is not included in the article's Creative Commons licence and your intended use is not permitted by statutory regulation or exceeds the permitted use, you will need to obtain permission directly from the copyright holder. To view a copy of this licence, visit http://creativecommons.org/licenses/by/4.0/. 
Phage preparations usually contain large amounts of bacterial endotoxin due to host cell lysis $(\mathrm{Gu}$ et al. 2011). Even small amounts of LPS (1 $\mathrm{ng} / \mathrm{mL})$ present in phage preparations can induce cytokine production, pyrogenic reactions, and septic shock in humans and experimental animals (Abaev et al. 2013; Romanovsky et al. 1996). Therefore, efficient removal of LPS from phage preparations is an ongoing challenge in the process of phage application.

Lytic phages can influence the gut microbiome by attacking and lysing bacterial target cells (Hsu et al. 2019). However, as temperate phages may mediate gene transfer from one bacterial cell to another, they are generally avoided for direct use as therapeutics (Gordillo Altamirano and Barr 2019; Górski et al. 2003). Phages can bypass multiple endothelial, mucosal, and epithelial cell barriers rapidly to achieve systemic distribution (Huh et al. 2019). The mechanism of phage penetration remains unclear and appears to be both phage and host species-specific (Oliveira et al. 2009; Prasuhn Jr. et al. 2008). Hypervariable Ig-like capsid proteins, when exposed by the T4 phage, mediated the interaction with the glycans of glycoproteins in the mucosa, resulting in a high concentration of phages in the mucus layer (Barr et al. 2013). It was shown that specific phages could pass through the fenestrae pores of intestinal epithelial tight junctions, enabling their rapid accumulation within highly vascularized organs, such as the liver, spleen, and bone marrow (Dąbrowska et al. 2005; Keller and Engley Jr. 1958). Furthermore, phage particles may be transported into the cell by receptor-mediated endocytosis, whereby a specific receptor on the cell surface binds tightly to an extracellular ligand that is displayed on the phage capsid (Barr 2017). Studying the distribution of phages in the gastrointestinal environment is an essential basis for understanding their role in the gut ecosystem. Limited data on the distribution of phages in the gut and their ability to enter the animal tissue and bloodstream remains a major problem. In recent years, research has focused increasingly on the regulatory role of phages in the gut ecosystem (Foca et al. 2015; ŁusiakSzelachowska et al. 2017). However, phage survival, as well as gut colonization and distribution in the gastrointestinal tract, are still poorly understood. This study aimed to elucidate the abundance and distribution of phage particles in the gastrointestinal tract when mice were orally fed phages for 1 month.

\section{Materials and methods}

\section{Large-scale preparation of phage suspensions}

The lytic phage PA13076 (GenBank accession number: MF740800.1) (Bao et al. 2020) and the temperate phage BP96115 (GenBank accession number: MG407615) were used in this study. Phage PA13076, originally isolated from chicken feces, was propagated by using $10^{6} \mathrm{CFU} /$ $\mathrm{mL}$ of $S$. Enteritidis ATCC 13076 and $10^{8} \mathrm{PFU} / \mathrm{mL}$ of PA13076 in $1000 \mathrm{~mL}$ TSB broth at $37^{\circ} \mathrm{C}$ without shaking for $6 \mathrm{~h}$. The temperate phage BP96115, originally induced from the pathogen $S$. Pullorum SPu-115 with mitomycin $\mathrm{C}(0.5 \mu \mathrm{g} / \mathrm{mL}$, final concentration), was propagated by incubation at $37^{\circ} \mathrm{C}$ for $4-5 \mathrm{~h}$ with shaking. $S$. Pullorum SPu-109, which was infected using culture supernatant after induction, was chosen as the host strain by using the spot test. In the host strain $S$. Pullorum SPu-109, the temperate phage BP96115 was propagated by using $10^{8} \mathrm{CFU} / \mathrm{mL}$ in $1000 \mathrm{~mL}$ of TSB broth for $6 \mathrm{~h}$ at $37^{\circ} \mathrm{C}$ without shaking. Crude phage lysates were obtained by centrifugation at $15000 \times \mathrm{g}$ for $10 \mathrm{~min}$ at $4{ }^{\circ} \mathrm{C}$. Subsequently, the supernatants were filtered through sterile $0.22 \mu \mathrm{m}$ filters (Merck Millipore Ltd., Ireland). Phage particles were precipitated using $\mathrm{NaCl}$ and PEG 8000, as previously described (Bao et al. 2015).

\section{LPS removal}

Phage particles $\left(10^{10} \mathrm{PFU} / \mathrm{mL}\right)$ in SM buffer $(50 \mathrm{mM}$ Tris- $\mathrm{HCl}[\mathrm{pH} 7.5], 0.10 \mathrm{M} \mathrm{NaCl}, 8 \mathrm{mM} \mathrm{MgSO}_{4} \cdot 7 \mathrm{H}_{2} \mathrm{O}$ and $0.01 \%$ gelatine) were added on top of discontinuous cesium chloride gradients ( $\mathrm{CsCl}$ gradient) $(1.3,1.5$, and $1.7 \mathrm{~g} / \mathrm{cm}^{3}$ ) and centrifuged at $40,000 \times \mathrm{g}$ for $4 \mathrm{~h}$ at $4{ }^{\circ} \mathrm{C}$ as previously described (Watanabe et al. 2007). The phage fraction was collected with a sterile syringe, dialyzed against sterile SM buffer overnight at $4{ }^{\circ} \mathrm{C}$, with $\mathrm{SM}$ buffer being changed once during dialysis.

The $\mathrm{CsCl}$-purified phages were treated with $1 \%$ deoxycholate detergent and incubated with shaking at $37^{\circ} \mathrm{C}$ for $60 \mathrm{~min}$. This was followed by ultrafiltration using Ultra-15 Centrifugal Filter Devices with a 100 KDa nominal molecular weight cut-off (NMWCO) membrane (Merck Millipore Ltd., Cork, Ireland), with centrifugation at $4000 \times g$ for $5 \mathrm{~min}$ at $4{ }^{\circ} \mathrm{C}$, which was done five times with washing using SM buffer (Jun et al. 2013). Finally, the phage suspension obtained from ultrafiltration was filtered through a sterile $0.22 \mu \mathrm{m}$ membrane (Merck Millipore Ltd., Ireland).

\section{Endotoxin quantitation in phage solutions}

The endotoxin contents of the raw phage lysate and the purified phage suspensions were analyzed using a Limulus Amebocyte Lysate (LAL) Chromogenic Endotoxin Quantitation kit (Thermo Fisher, Sweden) according to the manufacturer's protocol. The absorbance at $405 \mathrm{~nm}$ was measured using a plate reader (TECAN SUNRISE, Switzerland).

\section{Animals' experimental treatments}

C57BL/6 female mice (6-8 week-old) were purchased from the Comparative Medical Center of Yangzhou 
University (Yangzhou, China) and maintained under specific pathogen-free conditions in the experimental animal center in Jiangsu Academy of Agricultural Sciences (JAAS). JAAS approved the animal experiment following the guidelines provided by the Animal Care and Ethics Committee (SYXK 2015-2020). Mice were fed ad libitum with a commercial grain formulation (SHOOBREE Rat and Mouse Maintenance Diet, Jiangsu XieTong Organism Co., Ltd., Nanjing, China) and sterilized mineral water (Evian; pH 7.2; $\mathrm{HCO}_{3}{ }^{-}, 489 \mathrm{mg} / \mathrm{L}$ ).

After 2 weeks of acclimation, mice were assigned to three experimental treatments based on body weight ( $18 \mathrm{~g}$ ). The control group (20 mice) was separated from phage-treated mice and received no phage in their drinking water, the lytic group (20 mice) received purified lytic gut phage PA13076 in their drinking water at a concentration of ca. $1 \times 10^{8} \mathrm{PFU} / \mathrm{mL}$ (approx. $4 \times 10^{8}$ PFU per mouse daily as calculated from daily water uptake per animal), and the temperate group (20 mice) was treated with $1 \times 10^{8} \mathrm{PFU} / \mathrm{mL}$ (approx. $4 \times 10^{8} \mathrm{PFU}$ per mouse daily) of purified temperate phage BP96115 in sterilized mineral water. The drinking water with phage solutions was prepared once every day at the same time. Before administration, the phage suspensions were stirred well with a sterilized glass rod. This trial was conducted for 31 days.

\section{Sample collection}

After being weighed again, four mice from each group were humanely euthanized on day 16 and 31, respectively. For each mouse, $0.2 \mathrm{~mL}$ of blood was taken by puncturing the orbital plexus with a plastic tube containing $20 \mu \mathrm{L}$ heparin $(1000 \mathrm{U} / \mathrm{mL}$, Sigma, USA), while simultaneously adding $0.2 \mathrm{~mL}$ of blood into a tube without any anti-agglutination additive to produce serum. Six different segments of the gastrointestinal tract with their contents, including stomach, duodenum, jejunum, ileum, cecum, and colon, were isolated from mice and weighed prior to phage enumeration. All samples were collected aseptically. In addition, fecal samples were obtained on days 16 and 31 from each mouse before being euthanized.

\section{Phage detection and quantification}

Freshly collected feces were weighed and homogenized in a sterile plastic tube after the addition of sterile 10fold SM buffer. Each segment of the gastrointestinal tract with its contents and the spleen were homogenized in SM buffer with a tissue homogenizer (Shanghai Chemistry and Scientific Co. Ltd., Shanghai, China), making 10-fold diluted suspensions. The nonagglutinated blood $(0.2 \mathrm{~mL})$ was homogenized with $\mathrm{SM}$ buffer in a final volume of $1 \mathrm{~mL}$. After centrifugation at $12000 \times \mathrm{g}$ for $10 \mathrm{~min}$ at $4{ }^{\circ} \mathrm{C}$, these solutions were subjected to serial decimal dilution. The phage titers were determined using the double-layered plate method with S. Enteritidis ATCC 13076 or S. Pullorum SPu-109 as host cells. The detection limit was $50 \mathrm{PFU} / \mathrm{g}$.

\section{Determination of $\lg G$ in serum and secretory $\lg A$ in the ileum}

While IgG levels were determined in serum samples, secretory IgA (sIgA) levels were measured in ileum homogenates. Samples from day 31 were analyzed using a mouse IgG ELISA $(88-50,400)$ and a mouse IgA ELISA $(88-50,450)$ kit (eBioscience, San Diego, USA), according to the manufacturer's protocol. The absorbance was measured at $450 \mathrm{~nm}$ with a plate reader (TECAN SUNRISE, Switzerland).

\section{Statistical analysis}

Phage-treated samples were compared to the control group using one-way ANOVA. Significant differences were determined using Duncan's test with significance set at $p<0.01$. All data were analyzed using SPSS 22.0 (SPSS Inc., USA).

\section{Results}

\section{The endotoxin concentration of purified phages}

The endotoxin levels in the crude phage lysate exceeded $700 \mathrm{EU} / \mathrm{mL}$ for both phages (Table 1). After the phage suspensions were dialyzed following $\mathrm{CsCl}$-ultracentrifugation, still 16.72 and $20.25 \mathrm{EU} / \mathrm{mL}$ were detected. After detergent treatment and ultrafiltration, phage titers of PA13076 and BP96115 were $1 \times 10^{10} \mathrm{PFU} / \mathrm{mL}$, and sufficiently low endotoxin levels were reached. Thus, the concentration of endotoxin was reduced to $<1 \mathrm{EU} / \mathrm{mL}$, which is an acceptable range for in vivo applications (Table 1).

\section{Distribution of the phages in the gastrointestinal tract}

Significantly increased phage loads were detected in all analyzed gastrointestinal tract segments of treated mice for the lytic gut phage PA13076 (Fig. 1a), and the temperate phage BP96115 (Fig. 1b), indicating that both phages were transiently carried along the gastrointestinal tract. Most of the phages were destroyed by gastric acid, only about $10^{2} \mathrm{PFU} / \mathrm{g}$ of phage PA13076 and BP96115 survived when fed through drinking water. Generally, the phage titer in gastrointestinal tract samples from

Table 1 Endotoxin levels in different phage solutions (unit: EU/ $\mathrm{mL})$

\begin{tabular}{llll}
\hline Purification step & The phage solution & PA13076 & BP96115 \\
\hline 1 & Crude phage lysate & 748.54 & 912.20 \\
2 & CsCl-ultracentrifugation & 16.72 & 20.25 \\
3 & Ultrafiltrated & 0.86 & 0.91 \\
& Phage titer (PFU/mL) & $1 \times 10^{10}$ & $1 \times 10^{10}$ \\
\hline
\end{tabular}



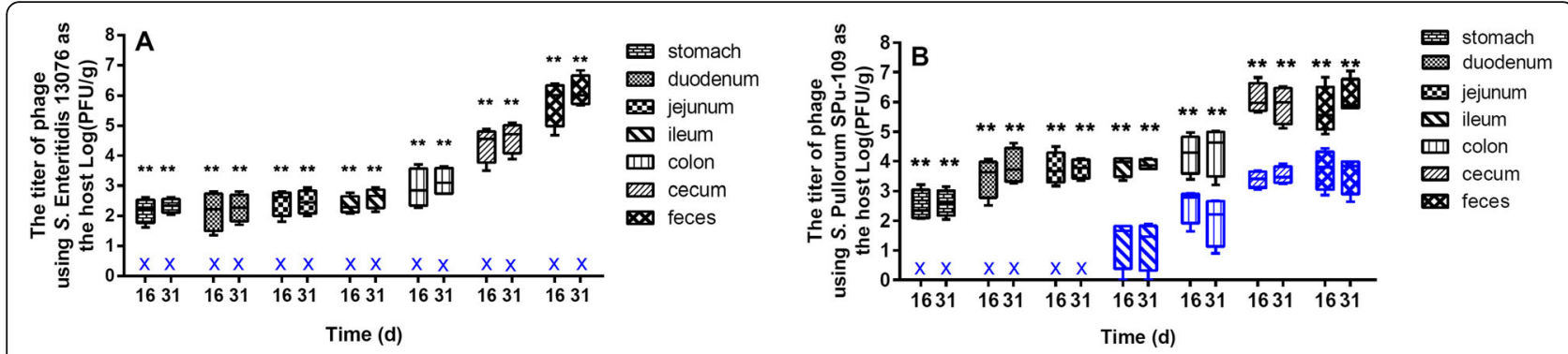

Fig. 1 Phage titers in the gastrointestinal tract of mice at day 16 and 31. The phage titer is expressed as the range and the mean log PFU/g for the specified gut segment (stomach, duodenum, jejunum, ileum, colon, cecum and feces) on day 16 and 31. a. The titer of phage PA13076 using S. Enteritidis 13,076 as the host. b. The titer of phage BP96115 using S. Pullorum SPu-109 as the host. Black color represents the lytic (a) and lysogenic (b), and blue color represents the control group, respectively. $\mathbf{X}$ represents phage titer values below the detection limit. ${ }^{* *}$ differed by $p<0.01$ between treated and control mice

mice treated with the lytic phage was lower than that of mice treated with the temperate phage in homologous samples, indicating that more lysogenic than lytic phages colonized the gut. No significant differences were observed between two time points (days 16 and 31) within analyzed segments of the gastrointestinal tract. Moreover, phages colonized the large intestine segment at more substantial titers $\left(10^{4}-10^{6} \mathrm{PFU} / \mathrm{g}\right)$ than the first part of the gastrointestinal tract $\left(10^{2}-10^{4} \mathrm{PFU} / \mathrm{g}\right)$.

\section{Phage recovery from blood and spleen samples}

Phage titers in the spleen were similar between PA13076 treated and BP96115 treated mice (Fig. 2a and b). The phage titers in whole blood samples ranged from $10^{2}$ to $10^{3} \mathrm{PFU} / \mathrm{mL}$, thus being lower than titers detected in spleen samples wherein almost $10^{4} \mathrm{PFU} / \mathrm{g}$ were detected.

The levels of IgG in serum and slgA in the ileum At day 31 of the phage treatment, increased IgG ( $p=$ $0.118)$ and $\operatorname{sIgA}(p=0.88)$ levels were detected in phage treated mice when compared to the control mice (Fig. 3).
However, even though no significant effect on the levels of serum IgG and ileal sIgA was observed, IgG and sIgA levels were higher in the lytic than in the temperate group.

\section{Discussion}

The present study confirmed that a combination of ultracentrifugation and ultrafiltration sufficiently removed bacterial LPS from phage solutions before using these for animal experiments, as reported previously (Dufour et al. 2016; Hudson et al. 2015). Previous studies showed that high phage concentrations could induce pro-inflammatory responses, while long-term exposure to phages induced an antibody response in the spleen (Hodyra-Stefaniak et al. 2015; Majewska et al. 2015). Therefore, an appropriate purification protocol is mandatory to reduce endotoxin levels to satisfy the requirements for phage clinical application (Simoliunas et al. 2015).

This study analyzed the abundance and distribution of orally administrated phages in the gastrointestinal tract when mice were exposed to a lytic and a lysogenic phage
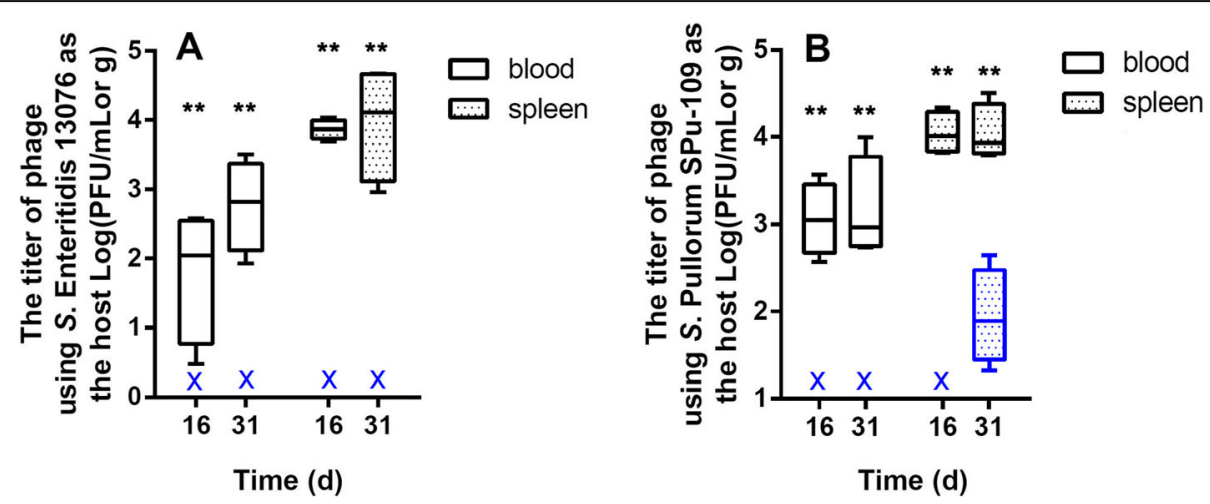

Fig. 2 Quantification of phages in blood and spleen of mice at day 16 and 31. The phage titers were quantified on day 16 and 31 . a. The titer of phage PA13076 using S. Enteritidis 13,076 as the host $(n=4)$. b. The titer of phage BP96115 using S. Pullorum SPu-109 as the host $(n=4)$. Black color represents the lytic (a) and lysogenic (b), and blue color represents the control group, respectively. $\mathbf{X}$ represents phage titer values below the detection limit. ${ }^{* *}$ differed by $p<0.01$ between treated and control mice 

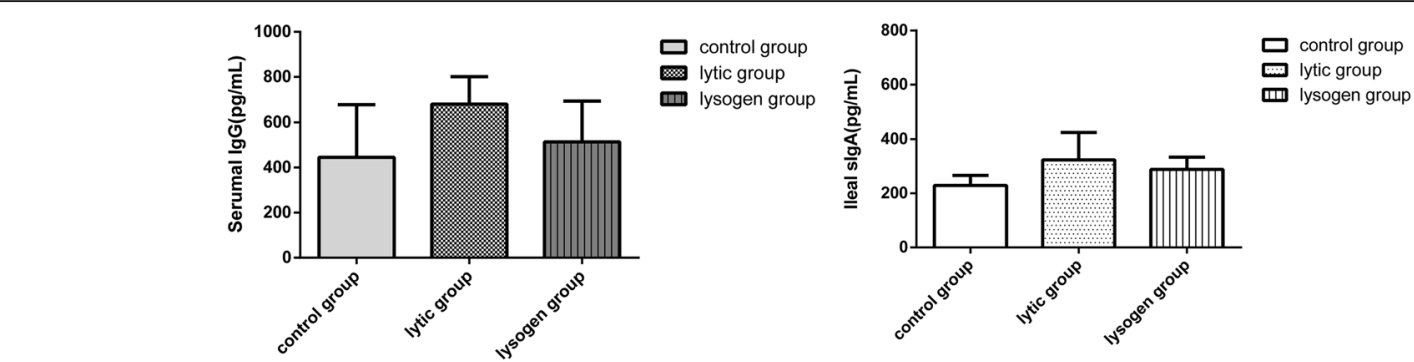

四 Iytic group

Insogen group

Fig. 3 The lgG levels in serum and the slgA levels in ileum samples at the end of the experiment (day 31). The results shown are the mean values of $\operatorname{lgG}$ or $\operatorname{sg} A$ in $\mathrm{pg} / \mathrm{mL}$. The standard deviation of the mean is indicated by error bars $(n=4)$

for 31 days. Oral administration of phages is mainly used to treat gastrointestinal infections and, in some cases, systemic infections (Ryan et al. 2011). The challenge is the phage stability in the highly acidic $(\mathrm{pH} \approx 1-2)$, anaerobic and proteolytic environment of the stomach (Atterbury et al. 2007; Ma et al. 2008; Maura et al. 2012). These unfavorable conditions can drastically reduce phage titers to be pharmacologically ineffective (Huh et al. 2019). For example, due to low stability at acidic $\mathrm{pH}$, six phages showing in vitro efficacy were not able to reduce Salmonella Typhimurium levels in vivo significantly, even when administered orally at $10^{9} \mathrm{PFU} / \mathrm{mL}$ (Albino et al. 2014). In previous trials, neutralizing agents, such as $\mathrm{CaCO}_{3}$ or $\mathrm{NaHCO}_{3}$, were fed concurrently or before phage administration to prevent acid inactivation. However, when healthy children received T4 phages $\left(10^{9} \mathrm{PFU} / \mathrm{mL}\right)$ in a bicarbonate solution, only low phage levels were recovered in feces (median $2 \times 10^{2}$ PFU/g feces) (Sarker et al. 2012). Even though this method enhanced phage transit from the stomach to other body sites, a pH-sensitive $S$. aureus phage could not be detected in the feces of rabbits, despite the use of a gastric acid inhibitor (ranitidine, $3 \mathrm{mg} / \mathrm{kg}$ ) before oral phage administration (Vandersteegen et al. 2011). Although the mice in the current study were administrated $4 \times 10^{8} \mathrm{PFU} /$ day continuously for 31 days in the lytic and temperate group, the viability of phages was rapidly lost upon exposure to gastric acid, as the titers of phages in the stomach were always $\leq 10^{3} \mathrm{PFU} / \mathrm{g}$. However, if phages are ingested along with food, the food matrix can protect a certain proportion of phage particles from inactivation and might speed up phage delivery across the stomach. Similarly, phage immobilization and microencapsulation did improve phage stability and survival after exposure to gastrointestinal conditions and transit (Ma et al. 2008; Soto et al. 2018).

Monitoring the gastrointestinal transit of phages may mirror intestinal phage dynamics (Zelasko et al. 2017). Albeit high phage shedding would indicate in vivo phage stability, viral replication and immune elimination of phages also affect measurable phage titers. A phage trial assessing oral phage therapy in 120 Bangladeshi children (6-24-months old) with diarrheal disease (Sarker et al. 2016) reported phage titers not exceeding $10^{6} \mathrm{PFU} / \mathrm{g}$ stool. In many subjects, the phage titer was only 1 PFU/ g stool, highlighting that sufficient phage presence in the gastrointestinal tract is needed to achieve efficient phage-mediated bacterial lysis, especially with respect to factors mediating in vivo phage replication during treatment.

In the current study, a lysogenic phage using $S$. Pullorum SPu-109 as the host was detected in the cecum of the control mice at up to $10^{4} \mathrm{PFU} / \mathrm{g}$, while the abundance of the lytic phage using S. Enteritidis 13076 as the host was below the limit of detection in the gut of control mice. This result matches a report by Dhillon et al. (1976), showing that temperate phages predominate in mammalian feces.

Orally administered phages will pass through the stomach into the intestine and then cross the gut mucosa before systemic circulation (Międzybrodzki et al. 2017). It has been confirmed that phages can translocate across the gut mucosal barriers and migrate to peripheral blood and local tissues (Abeles and Pride 2014; Górski et al. 2006). Indeed, E. coli phages can translocate to the blood much more effectively from the intestinal tract than from the stomach (Dąbrowska et al. 2005), and fluorescently labeled M13 phage particles accumulated at sites of bacterial infection within $24 \mathrm{~h}$ of retroorbital injection in mice (Bardhan et al. 2014). Among the still limited number of studies evidencing the transfer of orally administered phages to blood after oral administration, the case of the staphylococcal phage A5/80 is a well-established example (Majewska et al. 2015; Międzybrodzki et al. 2017). The presence of phages in spleen and whole blood samples of phage treated mice in the current study suggested that phages crossed the epithelial barrier and entered extraintestinal sites, even when applied via the oral route. Similarly, Nguyen et al. (2017) demonstrated by performing in vitro studies that the human gut, lung, liver, kidney, and brain cell layers were able to take up and traffic phages. Moreover, the same authors showed that phage transfer across cell layers had a preferential directionality, following apical- 
to-basolateral transport with approximately $0.1 \%$ of bacteriophages being transcytosed over a 2 -h period.

However, despite exposing mice over 31 days to phages, the phage titer in the gastrointestinal tract and blood only increased gradually, even though phage titers were evidently higher in treated than in control mice. Phages can induce an immune response, as they are recognized as foreign proteins and are rapidly eliminated from the systemic circulation by reticuloendothelial system clearance (Dąbrowska et al. 2005). The production of anti-phage antibodies and the inhibitory effect due to adaptive immunity are crucial factors controlling phage colonization and distribution in the animal body. IgA, produced in the intestinal system by the gut-associated lymphoid tissue, is considered as one of the hallmarks of the humoral immune system. Intestinal barrier disruption by foreign particles can elicit immune responses such as IgA production, which in turn can upregulate $\mathrm{T}$ and $\mathrm{B}$ cell production. A long-term study of antibody induction in mice with T4 phage particles applied per os over 100 days showed the presence of anti-phage antibodies (IgM, IgG, and secretory IgA) in treated animals, with high levels of such antibodies decreasing the phage concentrations in the blood of mice and hindering the gut transit of phage T4 (Majewska et al. 2015). However, several other studies based on oral phage application showed only weak immune responses in treated animals, suggesting that a limited increase in anti-phage antibodies does not hinder the positive outcome of phage therapy (Łusiak-Szelachowska et al. 2014; Zaczek et al. 2016). Even though, increased production of antiphage antibodies may limit the gut colonization by phages and, consequently, the efficacy of phage therapy. A recent study on the biosafety of phage therapy in piglets (Zheng et al. 2019) showed no significant biochemical variation regarding liver (alanine aminotransferase, aspartic transaminase, and $\gamma$-glutamyl transpeptidase) and renal functions (urea, creatinine, and bilirubin). Additionally, the same authors reported constant levels of immunoglobulin E (IgE), IgG, and histamine in these piglets, indicating that phage therapy did not induce allergic symptoms. Therefore, phage therapy could be considered safe for animals and humans.

The prevalence of phages in the gastrointestinal tract of mice was lower than $1 \%$ of the amount of ingested phages, indicating transient phage carriage, and lowlevel colonization in the gut. The highest phage titers were detected in the feces, with about $10^{6} \mathrm{PFU} / \mathrm{g}$ for PA13076 and BP96115 after phage treatment. Available evidence suggests that oral phage administration leads to passive transport through the gastrointestinal tract, with most phages recovered subsequently from the feces (Huh et al. 2019). Similarly, phage T3 preferentially absorbed in the upper or lower sections of the intestine
(Hoffmann 1965). Ma et al. (2016) demonstrated that the transient carriage of phage through the gastrointestinal tract of chickens occurred as indicated by a peak phage concentration in feces after $1.5 \mathrm{~h}$. In the current study, we assessed the colonization of the gastrointestinal tract of mice by phages after oral administration with ad libitum access to water for 31 days. The limited phage colonization of the mouse gut matched data reported by Ma et al. (2016), who assessed the temporal distribution of both encapsulated and free phages administered to young chicks, showing that both types of phages were present at levels ranging from $10^{2}$ to $10^{6}$ $\mathrm{PFU} / \mathrm{g}$ of gut contents along the entire gastrointestinal system. Low-level phage colonization in the small intestine of treated mice could be due to the segmented movement of gut contents or the absence of their host bacteria. This would suggest that multiple interval dosing may be required, or that the dosage could be increased during phage therapy.

\section{Conclusions}

A well-characterized lytic (PA13076) and a temperate phage (BP96115) were purified using ultracentrifugation and ultrafiltration before administration to mice. A small portion of administered phages survived exposure to gastric acid and entered the intestinal tract. Both phages were mainly located in the cecum and feces, with titers reaching up to $10^{4}$ and $10^{5} \mathrm{PFU} / \mathrm{g}$ in cecum for PA13076 and BP96115, respectively. Simultaneously, the phages were detected in blood and spleen samples of mice, and increased IgG and sIgA levels were observed. Even though the liver of phage treated mice was not analyzed in the present study, which is a limitation, it demonstrated transient phage carriage and low-level colonization of orally administrated lytic and temperate gut phages in mice.

\section{Abbreviations \\ LPS: Lipopolysaccharides; S. Enteritidis: Salmonella enterica serovar Enteritidis; S. Pullorum: Salmonella enterica serovar Pullorum; E.U.: Endotoxin unit; IgG: Immunoglobulin G; slgA: Secretory immunoglobulin A}

\section{Acknowledgments}

Not applicable.

\section{Authors' contributions}

HB formulated overarching research goals, designed experiments, and wrote the manuscript; $\mathrm{HB}, \mathrm{YZ}, \mathrm{MP}$, and $\mathrm{SZ}$ performed the experiments; $\mathrm{HZ}$ and $\mathrm{KS}$ analyzed data; AO reviewed, and RW and SS reviewed and edited the paper, and all authors interpreted the data and agreed to publish. The author(s) read and approved the final manuscript.

\section{Funding}

This study was supported by the National Natural Science Foundation of China (NSFC 31701725 and 31950410562), and the National Key R\&D Program of China (No. 2018YEE0101900).

Availability of data and materials

Please contact the corresponding authors for information. 


\section{Ethics approval and consent to participate}

All procedures involving animals were approved by the Animal Care and Ethics Committee of Jiangsu Academy of Agricultural Sciences (SYXK 20152020).

\section{Competing interests}

The authors declare that they have no conflict of interest.

\section{Author details}

'Key Laboratory of Control Technology and Standard for Agro-product Safety and Quality, Jiangsu Key Laboratory for Food Quality and Safety-State Key Laboratory Cultivation Base of Ministry of Science and Technology, Institute of Food Safety and Nutrition, Jiangsu Academy of Agricultural Sciences, Nanjing 210014, China. ${ }^{2}$ Discipline of Microbiology, School of Life Sciences, College of Agriculture, Engineering and Science, University of KwaZulu-Natal, Pietermaritzburg Campus, Private Bag X01, Pietermaritzburg 3201, South Africa. ${ }^{3}$ Discipline of Microbiology, School of Life Sciences, College of Agriculture, Engineering and Science, University of KwaZulu-Natal, Westville Campus, Private Bag X54001, Durban 4000, South Africa.

\section{Received: 15 April 2020 Accepted: 29 June 2020}

Published online: 29 July 2020

\section{References}

Abaev, I., Foster-Frey, J., Korobova, O., Shishkova, N., Kiseleva, N., Kopylov, P. Pryamchuk, S., Schmelcher, M., Becker, S. C., \& Donovan, D. M. (2013). Staphylococcal phage 2638A endolysin is lytic for Staphylococcus aureus and harbors an inter-lytic-domain secondary translational start site. Applied Microbiology and Biotechnology, 97, 3449-3456.

Abeles, S. R., \& Pride, D. T. (2014). Molecular bases and role of viruses in the human microbiome. Journal of Molecular Biology, 426, 3892-3906.

Ahmadi, M., Karimi Torshizi, M. A., Rahimi, S., \& Dennehy, J. J. (2016). Prophylactic bacteriophage administration more effective than post-infection administration in reducing Salmonella enterica serovar Enteritidis shedding in quail. Frontiers in Microbiology, 7, 1253.

Albino, L. A. A., Rostagno, M. H., Húngaro, H. M., \& Mendonça, R. C. S. (2014). Isolation, characterization, and application of bacteriophages for Salmonella spp. biocontrol in pigs. Foodborne Pathogens and Disease, 11, 602-609.

Atterbury, R. J., Van Bergen, M. A., Ortiz, F., Lovell, M. A., Harris, J. A., De Boer, A., Wagenaar, J. A., Allen, V. M., \& Barrow, P. A. (2007). Bacteriophage therapy to reduce salmonella colonization of broiler chickens. Applied and Environmental Microbiology, 73, 4543-4549.

Bao, H., Zhang, P., Zhang, H., Zhou, Y., Zhang, L., \& Wang, R. (2015). Bio-control of Salmonella Enteritidis in foods using bacteriophages. Viruses, 7, 4836-4853.

Bao, H., Zhou, Y., Shahin, K., Zhang, H., Cao, F., Pang, M., Zhang, X., Zhu, S., Olaniran, A., Schmidt, S., \& Wang, R. (2020). The complete genome of lytic Salmonella phage VB_SenM-PA13076 and therapeutic potency in the treatment of lethal Salmonella Enteritidis infections in mice. Microbiological Research, 237, 126471.

Bardhan, N. M., Ghosh, D., \& Belcher, A. M. (2014). M13 virus based detection of bacterial infections in living hosts. Journal of Biophotonics, 7, 617-623.

Barr, J. J. (2017). A bacteriophages journey through the human body. Immunological Reviews, 279, 106-122.

Barr, J. J., Auro, R., Furlan, M., Whiteson, K. L., Erb, M. L., Pogliano, J., Stotland, A., Wolkowicz, R., Cutting, A. S., Doran, K. S., et al. (2013). Bacteriophage adhering to mucus provide a non-host-derived immunity. Proceedings of the National Academy of Sciences of the United States of America, 110, 10771-10776.

Dhillon, T. S., Dhillon, E. K., Chau, H. C., Li, W. K., \& Tsang, A. H. (1976). Studies on bacteriophage distribution: virulent and temperate bacteriophage content of mammalian feces. Applied and Environmental Microbiology, 32, 68-74.

Dąbrowska, K., Switala-Jelen, K., Opolski, A., Weber-Dąbrowska, B., \& Górski, A. (2005). Bacteriophage penetration in vertebrates. Journal of Applied Microbiology, 98, 7-13.

Dufour, N., Henry, M., Ricard, J. D., \& Debarbieux, L. (2016). Commentary: Morphologically distinct Escherichia coli bacteriophages differ in their efficacy and ability to stimulate cytokine release in vitro. Frontiers in Microbiology, 7, 1029.

Foca, A., Liberto, M. C., Quirino, A., Marascio, N., Zicca, E., \& Pavia, G. (2015). Gut inflammation and immunity: What is the role of the human gut virome? Mediators of Inflammation, 2015, 326032.
Galtier, M., De Sordi, L., Maura, D., Arachchi, H., Volant, S., Dillies, M. A., \& Debarbieux, L. (2016). Bacteriophages to reduce gut carriage of antibiotic resistant uropathogens with low impact on microbiota composition. Environmental Microbiology, 18, 2237-2245.

Gordillo Altamirano, F. L., \& Barr, J. J. (2019). Phage therapy in the postantibiotic era. Clinical Microbiology Reviews, 32, e00066-e00018.

Górski, A., Nowaczyk, M., Weber-Dąbrowska, B., Kniotek, M., Boratynski, J., Ahmed, A., Dąbrowska, K., Wierzbicki, P., Switala-Jelen, K., \& Opolski, A. (2003). New insights into the possible role of bacteriophages in transplantation. Transplantation Proceedings, 35, 2372-2373.

Górski, A., Wazna, E., Dąbrowska, B. W., Dąbrowska, K., Switala-Jelen, K., \& Międzybrodzki, R. (2006). Bacteriophage translocation. FEMS Immunology and Medical Microbiology, 46, 313-319.

Gu, J., Lu, R., Liu, X., Han, W., Lei, L., Gao, Y., Zhao, H., Li, Y., \& Diao, Y. (2011). LysGH15B, the SH3b domain of staphylococcal phage endolysin LysGH15, retains high affinity to staphylococci. Current Microbiology, 63, 538-542.

Hodyra-Stefaniak, K., Miernikiewicz, P., Drapala, J., Drab, M., Jonczyk-Matysiak, E., Lecion, D., Kazmierczak, Z., Beta, W., Majewska, J., Harhala, M., et al. (2015). Mammalian Host-Versus-Phage immune response determines phage fate in vivo. Scientific Reports, 5, 14802.

Hoffmann, M. (1965). Animal experiments on the mucosal passage and absorption viremia of T3 phages after oral, tracheal and rectal administration. Zentralblatt für Bakteriologie, Parasitenkunde, Infektionskrankheiten und Hygiene. 1. Abt Medizinisch-hygienische Bakteriologie, Virusforschung und Parasitologie Originale, 198, 371-390.

Hsu, B. B., Gibson, T. E., Yeliseyev, V., Liu, Q., Lyon, L., Bry, L., Silver, P. A., \& Gerber, G. K. (2019). Dynamic modulation of the gut microbiota and metabolome by bacteriophages in a mouse model. Cell Host \& Microbe, 25, 803-814.e805.

Hudson, J. A., Billington, C., Wilson, T., \& On, S. L. (2015). Effect of phage and host concentration on the inactivation of Escherichia coli O157:H7 on cooked and raw beef. Food Science and Technology International, 21, 104-109.

Huh, H., Wong, S., St Jean, J., \& Slavcev, R. (2019). Bacteriophage interactions with mammalian tissue: Therapeutic applications. Advanced Drug Delivery Reviews, $145,4-17$.

Jun, S. Y., Jung, G. M., Yoon, S. J., Oh, M. D., Choi, Y. J., Lee, W. J., Kong, J. C., Seol, J. G., \& Kang, S. H. (2013). Antibacterial properties of a pre-formulated recombinant phage endolysin, SAL-1. International Journal of Antimicrobial Agents, 41, 156-161.

Keller, R., \& Engley, F. B. (1958). Fate of bacteriophage particles introduced into mice by various routes. Proceedings of the Society for Experimental Biology and Medicine, 98, 577-580.

Kim, K. H., Lee, G. Y., Jang, J. C., Kim, J. E., \& Kim, Y. Y. (2013). Evaluation of anti-SE bacteriophage as feed additives to prevent Salmonella enteritidis (S.E.) in broiler. Asian-Australasian Journal of Animal Sciences, 26, 386-393.

Łusiak-Szelachowska, M., Weber-Dąbrowska, B., Jónczyk-Matysiak, E., Wójciechowska, R., \& Górski, A. (2017). Bacteriophages in the gastrointestinal tract and their implications. Gut Pathogens, 9, 44.

Łusiak-Szelachowska, M., Żaczek, M., Weber-Dąbrowska, B., Międzybrodzki, R., Kłak, M., Fortuna, W., Letkiewicz, S., Rogóż, P., Szufnarowski, K., \& Jończyk-Matysiak, E. (2014). Phage neutralization by sera of patients receiving phage therapy. Viral Immunology, 27, 295-304.

Ma, Y., Islam, G. S., Wu, Y., Sabour, P. M., Chambers, J. R., Wang, Q., Wu, S. X. Y., \& Griffiths, M. W. (2016). Temporal distribution of encapsulated bacteriophages during passage through the chick gastrointestinal tract. Poultry Science, 95, 2911-2920.

Ma, Y., Pacan, J. C., Wang, Q., Xu, Y., Huang, X., Korenevsky, A., \& Sabour, P. M. (2008). Microencapsulation of bacteriophage Felix $\mathrm{O} 1$ into chitosan-alginate microspheres for oral delivery. Applied and Environmental Microbiology, 74, 4799-4805.

Majewska, J., Beta, W., Lecion, D., Hodyra-Stefaniak, K., Klopot, A., Kazmierczak, Z., Miernikiewicz, P., Piotrowicz, A., Ciekot, J., Owczarek, B., et al. (2015). Oral application of T4 phage induces weak antibody production in the gut and in the blood. Viruses, 7, 4783-4799.

Malik, D. J., Sokolov, I. J., Vinner, G. K., Mancuso, F., Cinquerrui, S., Vladisavljevic, G. T., Clokie, M. R. J., Garton, N. J., Stapley, A. G. F., \& Kirpichnikova, A. (2017). Formulation, stabilisation and encapsulation of bacteriophage for phage therapy. Advances in Colloid and Interface Science, 249, 100-133.

Maura, D., Morello, E., du Merle, L., Bomme, P., Le Bouguenec, C., \& Debarbieux, L. (2012). Intestinal colonization by enteroaggregative Escherichia coli supports long-term bacteriophage replication in mice. Environmental Microbiology, 14, 1844-1854. 
Międzybrodzki, R., Kłak, M., Jończyk-Matysiak, E., Bubak, B., Wójcik, A., Kaszowska, M., Weber-Dabrowska, B., Łobocka, M., \& Górski, A. (2017). Means to facilitate the overcoming of gastric juice barrier by a therapeutic staphylococcal bacteriophage A5/80. Frontiers in Microbiology, 8, 467.

Nguyen, S., Baker, K., Padman, B. S., Patwa, R., Dunstan, R. A., Weston, T. A., Schlosser, K., Bailey, B., Lithgow, T., Lazarou, M., et al. (2017). Bacteriophage transcytosis provides a mechanism to cross epithelial cell layers. mBio, 8 , e01874-e01817.

Oliveira, A., Sereno, R., Nicolau, A., \& Azeredo, J. (2009). The influence of the mode of administration in the dissemination of three coliphages in chickens. Poultry Science, 88, 728-733.

Piewngam, P., Zheng, Y., Nguyen, T. H., Dickey, S. W., Joo, H. S., Villaruz, A. E., Glose, K. A., Fisher, E. L., Hunt, R. L., Li, B., et al. (2018). Pathogen elimination by probiotic Bacillus via signalling interference. Nature, 562, 532-537.

Prasuhn Jr., D. E., Singh, P., Strable, E., Brown, S., Manchester, M., \& Finn, M. G. (2008). Plasma clearance of bacteriophage Qbeta particles as a function of surface charge. Journal of the American Chemical Society, 130, 1328-1334.

Romanovsky, A. A., Shido, O., Sakurada, S., Sugimoto, N., \& Nagasaka, T. (1996). Endotoxin shock: thermoregulatory mechanisms. The American Journal of Physiology, 270, R693-R703.

Ryan, E. M., Gorman, S. P., Donnelly, R. F., \& Gilmore, B. F. (2011). Recent advances in bacteriophage therapy: how delivery routes, formulation, concentration and timing influence the success of phage therapy. The Journal of Pharmacy and Pharmacology, 63, 1253-1264.

Sarker, S. A., McCallin, S., Barretto, C., Berger, B., Pittet, A. C., Sultana, S., Krause, L., Huq, S., Bibiloni, R., Bruttin, A., et al. (2012). Oral T4-like phage cocktail application to healthy adult volunteers from Bangladesh. Virology, 434, 222232.

Sarker, S. A., Sultana, S., Reuteler, G., Moine, D., Descombes, P., Charton, F., \& Brüssow, H. (2016). Oral phage therapy of acute bacterial diarrhea with two coliphage preparations: A randomized trial in children from Bangladesh. EBioMedicine, 4, 124-137.

Simoliunas, E., Vilkaityte, M., Kaliniene, L., Zajanckauskaite, A., Kaupinis, A., Staniulis, J., Valius, M., Meskys, R., \& Truncaite, L. (2015). Incomplete LPS core-specific FelixO1-like virus vB_EcoM_VpaE1. Viruses, 7, 6163-6181.

Soto, M. J., Retamales, J., Palza, H., \& Bastias, R. (2018). Encapsulation of specific Salmonella Enteritidis phage f3aSE on alginate-spheres as a method for protection and dosification. Electronic Journal of Biotechnology, 31, 57-60.

Vandersteegen, K., Mattheus, W., Ceyssens, P. J., Bilocq, F., De Vos, D., Pirnay, J. P., Noben, J. P., Merabishvili, M., Lipinska, U., Hermans, K., et al. (2011). Microbiological and molecular assessment of bacteriophage ISP for the control of Staphylococcus aureus. PLoS One, 6, e24418.

Watanabe, R., Matsumoto, T., Sano, G., Ishii, Y., Tateda, K., Sumiyama, Y., Uchiyama, J., Sakurai, S., Matsuzaki, S., Imai, S., et al. (2007). Efficacy of bacteriophage therapy against gut-derived sepsis caused by Pseudomonas aeruginosa in mice. Antimicrobial Agents and Chemotherapy, 51, 446-452.

Zaczek, M., Łusiak-Szelachowska, M., Jónczyk-Matysiak, E., Weber-Dąbrowska, B., Międzybrodzki, R.r Owczarek, B., Kopciuch, A., Fortuna, W., Rogoz, P., \& Górski, A. (2016). Antibody production in response to Staphylococcal MS-1 phage cocktail in patients undergoing phage therapy. Frontiers in Microbiology, 7, 1681.

Zelasko, S., Górski, A., \& Dąbrowska, K. (2017). Delivering phage therapy per os: benefits and barriers. Expert Review of Anti-Infective Therapy, 15, 167-179.

Zheng, D., Dong, X., Pan, P., Chen, K., Fan, J., Cheng, S., \& Zhang, X. (2019). Phageguided modulation of the gut microbiota of mouse models of colorectal cancer augments their responses to chemotherapy. Nature Biomedical Engineering, 3, 717-728.

\section{Publisher's Note}

Springer Nature remains neutral with regard to jurisdictional claims in published maps and institutional affiliations.

Ready to submit your research? Choose BMC and benefit from:

- fast, convenient online submission

- thorough peer review by experienced researchers in your field

- rapid publication on acceptance

- support for research data, including large and complex data types

- gold Open Access which fosters wider collaboration and increased citations

- maximum visibility for your research: over $100 \mathrm{M}$ website views per year

At BMC, research is always in progress.

Learn more biomedcentral.com/submissions 